Poster Presentation Abstracts

to first-line anticonvulsants. For term neonates a dosing regimen has been developed (Malingré et al., 2006), but it has not been evaluated for preterm neonates. The objective of this study was to develop an optimal dosing strategy for lidocaine in preterm and term neonates on basis of a newly developed population PK model.

Methods: Simulations were performed using NONMEM 6.2. Several requirements were defined:

1) The dosing strategy should be safe to be implemented on a NICU;

2) Seizure control requires rapid adequate plasma concentrations;

3) Only a short duration of dosing is required, however, doses should be reduced slowly to decrease the risk of neurological withdrawal symptoms;

4) a target plasma concentration of 6 to $7 \mathrm{mg} / \mathrm{L}$ is preferred by the clinicians;

5) plasma concentrations $>9 \mathrm{mg} / \mathrm{L}$ are associated with cardiac arrhythmias and should be avoided.

Results: A body weight-based infusion strategy was developed using simulations. First, a bolus injection was chosen for all weight categories for rapid achievement rapid seizure control. This was followed by a 4-hour loading infusion. Then dosing was reduced in two steps during 6 and 12 hours, respectively. (regimen not shown)

With this regimen, the median concentration achieved at the end of the 4-hour infusion was 6.3 $\mathrm{mg} / \mathrm{L}$, (IQR $1.8 \mathrm{mg} / \mathrm{L})$. Only $3.6 \%$ of the simulated individuals had concentrations $>9.0 \mathrm{mg} / \mathrm{L}$.

This new strategy should be a safe and effective regimen for neonatal seizure control. Prospective validation is in progress.

480

\section{ACTIVITY OF CYP3A IN MOTHERS AND THEIR NEWBORNS USING 4B-HYDROXYCHOLESTEROL AS A MARKER}

\author{
K. Wide ${ }^{1}$, S. Ekmark-Sergel ${ }^{1}$, H. Nylen ${ }^{2}$, \\ U. Diczfalusy², L. Bertilsson²
}

${ }^{1}$ Div of Pediatrics, CLINTEC, Karolinska Institute, Stockholm, ${ }^{2}$ Department of Laboratory Medicine,

Karolinska Institute, Stockkholm, Sweden

Background: Pregnancy increases the activity of cytochrome P4503A (CYP3A). These enzymes metabolize several endogenous substances, e.g. cholesterol, which is converted into 4bhydroxycholesterol (4b-OHchol). We have suggested that $4 \mathrm{~b}-\mathrm{OH}$ chol can be used as a marker for CYP3A activity.

Aim: To study the activity in CYP3A in pregnant women and their infants by using $4 \mathrm{~b}-\mathrm{OH}$ chol as a marker.

Methods: 21 women and their 22 newborn infants (one pair of twins) were recruited at the delivery ward at Karolinska University Hospital, Huddinge. Levels of $4 \mathrm{~b}-\mathrm{OH}$ chol were determined in mothers and children from delivery to $72 \mathrm{~h}$ postpartum. 14 infants were born vaginally and 8 by elective caesarean section (CS). Follow-up after 3 months was performed in 10 mother-child pairs.

Results: Median levels of $4 \mathrm{~b}-\mathrm{OH}$ chol were increased in pregnant women compared to healthy adults. 3 months after delivery $4 \mathrm{~b}-\mathrm{OHchol}$ was still elevated in women giving birth vaginally. In contrast, women giving birth by CS had normal levels. Children born vaginally had significantly higher levels of $4 \mathrm{~b}-\mathrm{OH}$ chol compared to children born with elective CS, but both groups had lower levels than healthy adults. There was a significant increase in $4 \mathrm{~b}-\mathrm{OH}$ chol levels in both groups after 3 months.

Conclusion: Pregnancy activates the CYP3A enzymes. In newborns 4b-OHchol levels are low, but already after three months the children have CYP3A-activities comparable to that of healthy adults. Children born vaginally have higher levels of $4 \mathrm{~b}-\mathrm{OH}$ chol at birth, than children born with CS.

481

\section{CAN A GENTAMICIN SPECIFIC CHART REDUCE NEONATAL MEDICATION ERRORS?}
C. Flannigan'1, S. Kilpatrick², J. Redpath², M. Hogan²

${ }^{1}$ Neonatology, Royal Jubilee Maternity Hospital, Belfast, ${ }^{2}$ Neonatology, Craigavon Area Hospital, Portadown, UK

Background and aims: Since the onset of incident reporting, medication errors have been noted to be one of the most common reasons for reporting a clinical incident and antibiotics have been shown to be one of the most common drugs associated with medication error in children. This trend was also noted in the neonatology department in Craigavon Area Hospital, a busy district general 
Poster Presentation Abstracts

hospital with 3900 deliveries per year. The aim is to evaluate whether the introduction of a gentamicin prescription, administration and monitoring chart reduces the number of medication errors.

Methods: A retrospective audit looking at all the reported clinical incidents forms involving gentamicin over a 7 year period between 2002 and 2008 .

Results: Since the introduction of the new chart in 2005 there was a $16 \%(0.75)$ reduction in the average annual number of medication errors involving gentamicin from 4.75 to 4.00 . There were no further incidents recorded where the wrong dose of gentamicin was given or where a dose was given despite a high serum concentration. There has also been a $67 \%$ reduction in incidents where a gentamicin level was not monitored as required.

Conclusions: There has been some improvement in the number of gentamicin-based clinical incidents with the introduction of a gentamicin-specific chart, however errors are still occurring. Recommendations include the introduction of regular training on appropriate gentamicin prescribing for new staff and a mandatory yearly update for permanent staff. There is a plan to re-audit this yearly, with consideration of electronic prescribing.
482

\section{SAFETY AND EFFICACY OF VELAGLUCERASE ALFA IN GAUCHER DISEASE TYPE 1 PATIENTS PREVIOUSLY TREATED WITH IMIGLUCERASE}

G. Grabowski ${ }^{1}$, G. Pastores², R. Mardach ${ }^{3}$, C. Eng ${ }^{4}$, L. Smith ${ }^{5}$, P. Fernhoff 6 , J. Charrow ${ }^{7}$, M. Heisel-Kurth ${ }^{8}$, N. Longo ${ }^{9}$, W. Rhead ${ }^{10}$, P. Harmatz ${ }^{11}$, A. Mehta ${ }^{12}$, P. Giraldo ${ }^{13}$, A. Tylki-Szymanska ${ }^{14}$, A. Zimran ${ }^{15}$, E. Crombez ${ }^{16}$

${ }^{1}$ Cincinnati Children's Hospital Medical Center, Cincinnati, OH, ${ }^{2} \mathrm{NYU}$ School of Medicine, New York, NY, ${ }^{3}$ Kaiser Permanente Medical Center, Los Angeles, CA, ${ }^{4}$ Baylor College of Medicine, Houston, TX, ${ }^{5}$ Children's Mercy Hospital, Kansas City, MO, ${ }^{6}$ Emory University, Decatur, GA, ${ }^{7}$ Children's Memorial Hospital, Chicago, IL, ${ }^{8}$ Children's Hospitals of Minnesota, Minneapolis, MN, ${ }^{9}$ University of Utah, Salt Lake City, UT, ${ }^{10}$ Children's Hospital of Wisconsin, Milwaukee, WI, ${ }^{11}$ Children's Hospital Oakland, Oakland, CA, USA, ${ }^{12}$ Royal Free Hospital, London, UK, ${ }^{13}$ Hospital Universitario Miguel Servet, Zaragoza, Spain, ${ }^{14}$ Children's Memorial Health Institute, Warszawa, Poland, ${ }^{15}$ Shaare Zedek Medical Center, Jerusalem, Israel, ${ }^{16}$ Shire Human Genetic Therapies, Cambridge, MA, USA

Objective: To examine safety and efficacy of velaglucerase alfa every other week in patients with Gaucher disease previously receiving imiglucerase.

Methods: This open-label, multicenter, 12-month study, enrolled 41 patients $\geq 2$ years to receive velaglucerase alfa at a dose equalling their prior imiglucerase regimen, with infusions administered over 1-hour.

Results: Forty patients received study drug (18 male, 22 female; 4 previously splenectomized; age range, $9-71$ years, $25 \%<18$ years). Median prior imiglucerase use was 67 months (range 22-192 months). Velaglucerase alfa doses were: $\leq 22.5 \mathrm{U} /$ $\mathrm{kg} \quad(\mathrm{n}=14), 22.5-37.5 \mathrm{U} / \mathrm{kg} \quad(\mathrm{n}=12), 37.5-52.5 \mathrm{U} / \mathrm{kg}$ $(n=7)$, and $>52.5 \mathrm{U} / \mathrm{kg}(\mathrm{n}=7)$. Velaglucerase alfa was generally well tolerated with most AEs of mild or moderate severity. No patient experienced a lifethreatening $A E ; 7$ severe AEs (in 5 patients), and 5 treatment-emergent serious AEs (in 4 patients) were reported. One patient discontinued due to a hypersensitivity reaction; this patient did not have $\lg G$ or $\lg E$ antibodies. No patients developed $\lg G$ antibodies to velaglucerase alfa. Clinical parameters 